\title{
Not quite a revolution: Scrutinizing organizational neuroscience in leadership studies
}

\section{Dirk Lindebaum}

University of Liverpool, UK

\section{Mike Zundel}

University of Liverpool, UK

\begin{abstract}
Several provocative studies on organizational neuroscience have been published of late, many in the domain of leadership. These studies are motivated by the prospect of being able to better explain what causes and constitutes 'good' leadership by examining brain activity. In so doing, these studies follow an established path in organizational research that seeks to reduce complex social phenomena to more basic (neurological) processes. However, advocates of organizational neuroscience reveal very little about the fundamental problems and challenges of reductionism. Therefore, our aim in this article is to scrutinize the reductionist assumptions and processes underlying the fastevolving domain of organizational neuroscience as it is applied to the study of leadership. We maintain that without explicit consideration of, and solutions to, the challenges of reductionism, the possibilities to advance leadership studies theoretically and empirically are limited. In consequence, inferential ambiguities that flow from such insights run the danger of informing organizational practice inadequately. Thus, we find suggestions that we are at the brink of a neuroscientific revolution in the study of leadership premature, and a sole focus on neuroscience, at the expense of insights from other social science disciplines, dangerous.
\end{abstract}




\section{Keywords}

leadership, levels of analysis, organizational neuroscience, philosophy of science, quality of inferences, reductionism

\section{Introduction}

In this article, we ${ }^{1}$ seek to challenge the current advocacy of organizational neuroscience, especially in the domain of leadership research (Balthazard et al., 2012; Lee et al., 2012b; Senior et al., 2011; Waldman et al., 2011). We do so by scrutinizing the reductive assumptions and processes of organizational neuroscience as applied to the study of leadership. This challenge is both timely and imperative vis-a-vis largely unidentified or unresolved theoretical and practical issues associated with reductionism in organizational neuroscience. Accordingly, we are concerned about the quality of inferences drawn from this research and how they inform organizational practice.

The advocacy of reductionism in organizational neuroscience is often expressed along the following lines. For instance, some scholars maintain that neuroscientific research affords a better understanding of the relationship between 'organizational behavior and our brains and allows us to dissect specific social processes at the neurobiological level and apply a wider range of analysis to specific organizational research' (Senior et al., 2011: 804). By the same token, Becker et al. (2011: 934, emphasis added) suggest that neuroscience can 'elucidate particular networks of brain systems and processes responsible for the workplace attitudes and behaviors that organizational scholars have observed. Neuroscience can allow us to finally go inside the brain and investigate these primal causes of behavior'. In all this excitement, some leadership scholars even go as far as to ponder whether, by using neuroscience, we can 'revolutionize the way that inspirational leaders are identified and developed?' (Waldman et al., 2011: 60). Therefore, neuroscientific approaches follow the well-trodden path in management research that yield the identification and analysis of more basic mechanisms that are assumed to give rise to higher order organizational phenomena (Felin et al., in press; Nicholson and White, 2006).

In support of reductionism, Becker et al. (2011: 936, emphasis added) claim that 'hierarchical reductionism is a proper goal of science, since an explanation at one level of abstraction will inevitably lead to questions that are better answered at other levels'. ${ }^{2}$ Becker et al. (2011) invoke Pinker's account of hierarchical reductionism, which 'consists not of replacing one field of knowledge with another but of connecting or unifying them' (Pinker, 2002: 70, emphasis in original). Becker et al. (2011) also highlight a number of potential concerns about such reductive approaches. For instance, they acknowledge the possibility that the pursuit of molecular explanations potentially supplants other forms of social science inquiry, especially when scholars focus upon 'mechanisms within mechanisms within mechanisms' (Franklin, 1987: 202). Yet, for Becker et al. (2011), such concerns seem to fall short of comprehending the ultimate benefits and advances associated with the explanatory power of such lower-level phenomena. These insights are seemingly possible because neuroscience reduces organizational phenomena to what is considered to be a common denominator i.e. neural processes, which are mostly homogenous across all individuals - and these are suggested to underlie a wide range of varying situations at work (Becker et al., 2011). More specifically, organizational neuroscience is proposed to 
be able to reduce what some scholars see as variously layered, recursive and theoretically complex interactions between leaders and followers (Cunliffe, 2009; Cunliffe and Eriksen, 2011) to a set of linear, sequential patterns of limited variety, such as the dichotomous outputs (i.e. firing/dormant) of neurons. Through this reduction in complexity, otherwise difficult to study social affairs can be readily subjected to scientific analysis.

Therefore, the neuroscientific approach to management research can be understood in terms of a two-fold movement that first 'deconstructs individuals to discrete brain processes' (Becker et al., 2011: 936), effectively erasing extant units of analysis, such as culture, organizations or individuals from the explanatory vocabulary, while providing scientists with brain patterns that can be analysed through neuroscientific methods. By subsequently reconstructing brain-level phenomena into higher-level explanations, this type of neuroscientific analysis, but also neuroscientific interventions (e.g. Waldman et al., 2011), are thought to extend existing leadership theories, encourage new research directions and resolve existing conceptual disagreements (Becker et al., 2011).

However, there are also long-standing reservations against the reductionist spirit in the social sciences, and a number of serious concerns have been raised against the efficacy, applicability, as well as the implications of such approaches (see Guba and Lincoln, 1994; Nagel, 1974, 1998). When we extend these concerns to the field of organizational neuroscience, we are urged to question the putative possibilities and benefits of reductionism in the neuroscientific study of leadership. We elaborate upon these reservations in the course of our article.

The following three aspects bear great importance in our critique. First, our position closely aligns with that of Hobfoll (2001), who maintains that:

the moment we are seduced into thinking that any one level of analysis is the primary active agent, we forestall the scientific process and acquire scientific tendencies to guard the borders of our theories against the veracity of broader perspectives. (Hobfoll, 2001: 339)

Applied to our scrutinizing analysis, we argue that a predominant focus upon neuroscience to the study of leadership as an individual difference (see Waldman et al., 2011) excludes further important units of analysis, as well as relational and recursive aspects of organizational life (Cunliffe, 2009; Cunliffe and Eriksen, 2011). Consequently, we maintain that an unbridled pursuit of organizational neuroscience is more likely to impoverish rather than enrich our substantive understanding of leadership.

Second, and related to the first point, we argue that a more appropriate ontological locus of leadership resides in the dyadic relationship between a leader and follower - as opposed to a leader-centric (Antonakis et al., 2011) or follower-centric locus (Meindl, 1995). Specifically, we concur that existing research on dyadic relationships at work (i.e. between a leader and follower) often reflects a misalignment between theory and measurement (Krasikova and LeBreton, 2012). That is, even though a construct is theorized as dyadic, scholars often obtain data from one source only (e.g. follower perceptions of trust), while not being sufficiently sensitive to contextual nuances (see Lindebaum and Fielden, 2011). Our appreciation of the dyadic nature of leadership, coupled with the need to be contextually sensitive, is incongruent with the predominant view of organizational neuroscientists who view leadership largely as residing in the leader (e.g. Waldman et al., 2011).

Third, our challenge draws upon the philosophy of science (e.g. Nagel, 1998) and experimental psychology literature (e.g. Zajonc, 1984) as a bedrock for our scrutiny. 
Reductionism is a key subject in the philosophy of science. The notion of reductionism entails that there exists, in principle, a 'theory of everything' (Nagel, 1998) and scholars have developed numerous accounts and frameworks of reductionism (e.g. Feyerabend, 1962; Nagel, 1961). One comprehensive classification of different types of reductions is provided by Sarkar (1992), who distinguishes between: (i) theoretical, (ii) constitutive (or ontological) and (iii) explanatory reductions. We base our subsequent analysis upon this classification in order to highlight key assumptions in each category - and how they inform challenges and implications of neuroscientific leadership research. We conclude our analysis by synthesizing the theoretical implications and foreshadow their impact upon organizational practice.

\section{Theory reduction}

\section{Background}

A key aspect of organizational neuroscience is the reducibility of higher-order, social theories to what are considered to be more fundamental theories of brain processes (Becker et al., 2011; Waldman et al., 2011). However, in one of the earliest comprehensive analyses of reductive processes, Ernst Nagel (1961) recognizes that the connectability of different theoretical layers is not necessarily straightforward. Theory reduction implies 'the explanation of a theory or a set of experimental laws established in one area of inquiry, by a theory usually though not invariably formulated for some other domain' (Nagel, 1961: 338). The connectability of two areas depends upon the fit between the different 'systems of statements', as well as the formalized laws in both domains (see also Kaiser, 2012). Depending upon such a fit, Nagel (1961) distinguishes homogenous or heterogeneous forms of reduction.

In homogeneous reductions, the reduced theory and its 'absorbing', lower-level theory utilize substantially the same terms, and hence terminologies on both levels correlate with each other. In heterogeneous reductions, on the other hand, the reduced theory cannot be derived logically from the laws of the reducing theory. For instance, the reduction of thermodynamics to statistical mechanics involves heterogeneous terminologies (e.g. 'temperature' and 'statistical distribution', respectively; see Fazekas, 2009: 305). To connect the different layers, heterogeneous reductions require additional 'bridging laws' that correlate the terminologies of both domains (Nagel, 1961: 354). This means that one would need to articulate such a law to 'bridge' the notion of temperature - understood as movement between molecules (which is a non-statistical function) - with average values of statistical mechanics. There are substantial difficulties in establishing clear and unequivocal bridges - a fact highlighted by the ongoing discussions about the possibility of such derivations (Fazekas, 2009).

\section{Relevance to neuroscientific study of leadership}

We can explicate the problems of bridge laws by referring to Becker et al.'s (2011) account of mirror neurons, and how their analysis can potentially expand organizational theories. Mirror neurons denote a complex and largely unconscious brain process, which 
continuously monitors the behaviours and affective states of other individuals. This is suggested to afford the generation of 'automatic and nonconscious social ties between individuals' (Becker et al., 2011: 939). Mirror neurons are, therefore, argued to explain the contagion of emotions in groups and the affective partaking of individuals in emotional states of others, whether they are aware of it or not. For instance, in the context of workplace discrimination, the behaviour of mirror neurons is suggested to represent the 'deeper causes' of such behaviour, residing in the 'deep-brain structures of the limbic system' (Becker et al., 2011: 941). In their appended primer on neuroscience, Becker et al. depict this limbic system graphically as part of the temporal lobe and describe its functioning in terms of dichotomous outputs of neurons (dormant/fire; see Becker et al., 2011: 953-954), once certain thresholds have been reached.

But how do mirror neurons explain the workings of implicit assumptions and attitudes held by leaders in organizational contexts? To investigate this question, we have to understand how we can get from acts of 'discrimination' observed in leaders' unconscious, or tacit behaviours to the activity of neurons in particular parts of the brain. Applying Nagel's (1961) criteria, it is apparent that the theoretical connections between neuroscientific processes and leadership phenomena are heterogeneous in two important ways. First, there are different semantic and context-theoretical conceptions. For instance, even though both domains refer to 'tacit' aspects, the meaning attached to this concept differs strongly. Becker et al. invoke the neuro-biomedical idiom of brain topologies typically particular areas visible in brain scans. By contrast, relational leadership scholars invoke vocabularies that differ significantly from those of neuroscientists, for instance, when they associate tacitness with 'knowing-from-within interactive moments' (Cunliffe and Eriksen, 2011: 1433, emphasis in original), or with understanding of momentary subtleties to develop new approaches to 'acting, looking, listing, talking, evaluating' (Shotter, 2010: 160). Second, there are different kinds of logic in the conceptualization of the relationships involved. Neuroscientific analyses operate largely on the basis of binary logics, indicating active (firing) or passive (dormant) states of neurons. The explanatory construct is animated through linear and sequentially unfolding processes, for instance, when environmental stimuli trigger neurons to fire and thereby, subsequently, cause or influence human behaviour (see also Becker et al., 2011: 952). Leadership scholars across a range of ontological traditions, on the other hand, eschew binary logics when characterizing the relational and reciprocal character of leader and follower exchanges. For instance, discourse scholars show that high quality leader-member exchanges come into genesis 'dialogically' (Fairhurst, 2009: 1611), including role negotiations, and non-routine problem solving. Unlike linear and unidimensional processes, leaders are involved in contexts that are multi-layered, transforming dynamically with every action a leader and follower does - or does not take. Similarly, Cunliffe (2009: 95) investigates reflexive accounts of leadership as 'selves-in relation-to-others'. Elsewhere, she adds that leadership is 'embedded in the everyday relationally-responsive dialogical practice of leaders' (Cunliffe and Eriksen, 2011: 1425). In these accounts, leadership entails past experiences and future expectations that can shift with every relational interaction. Even psychologists have bemoaned of late that, albeit many phenomena of interest to applied psychological studies have a dyadic core (e.g. leader-member exchange), the relational side of these dyadic constructs is 
oftentimes not adequately examined empirically (Krasikova and LeBreton, 2012). Consequently, a misalignment between theory and measurement occurs if leader-member exchanges are theorized as relational but data are only collected from the follower (e.g. perception of trust toward the leader).

Returning to Nagel's (1961) bridge laws, we argue that there is a lack of 'fit' between the terminologies and logics of organizational and neuroscientific theories. We, therefore, require additional qualifications to connect the otherwise disparate domains and to provide 'co-reference' for the different theories and their heterogeneous vocabularies and logics. This means that links from higher-level descriptors to lower-level explanations (e.g. from the perception of an angry face to patterns of brain activation; see Lee et al., 2012a), or from the execution of controlled cognitive processes to the activities in the prefrontal cortex (Becker et al., 2011), have to be made explicit and qualified in a way that ensures that the terminological and structural logic of leadership research is coherently and comprehensively represented (i.e. 'bridged') at the neuroscientific level. Such qualifiers must, therefore, include statements that unequivocally relate the reciprocal logic and complex terminology of leader-follower interactions to patterns of dormant/firing states of neurons.

However, this bridging law condition is not trivial. Formulating statements that universally and unambiguously link, for instance, particular locations in the brain with socio-relational concepts, opens up a variety of further ambiguities. For instance, even a simply constructed 'bridge law' of the form 'neural activity in the temporal lobe (mirror neurons) indicates increased discrimination in leaders' decision making' requires further definitions and clarifications to explain their workings. For example, it would be nonsensical to suggest that a 50 per cent rise in neural activity means a 50 per cent rise in exercised 'discrimination' by leaders. Whereas the first measure is one of quantity, we would struggle to express the various and changing facets of discrimination in a workplace in terms of one linear, numerical scale. This bridge law would thus require a set of further clarifications.

The complexity and required depth of these additional statements could, therefore, considerably lessen the degree of simplicity for which the reduction was initially intended, resulting, at best, in complex sets of correlative qualifications, and, at worst, in an infinite regression of qualifiers (Schouten and de Jong, 2007). The question, therefore, remains whether and how social phenomena, such as 'leadership' or 'power', can be translated into a language and logic of neuroscience consisting of neurons that cannot 'lead' or be 'powerful', because the attachment of social predicates to a set of chemical reactions is nonsensical.

For these reasons we suggest that it is impossible to logically and consistently correlate what is measured on a neuroscientific level with the relational and socially complex phenomenon of leadership. Moreover, we argue that the impossibility of bridging the leadership/neuroscience schism is not merely a matter of degree and, in consequence, an issue that can be resolved once technological advances afford computation of greater complexity. Instead, we suggest that there are different 'logical types' at play (Bateson, 1972: 180) - that is, differences in kind whose conflation or even correlation poses insurmountable problems. If this holds true, it may mean that attempted reductions are bound to fail, thus calling into question the quality of inferences drawn. 


\section{Constitutive reductions}

\section{Background}

A second form of reduction is based on the assumption of ontological links, where lowerlevel phenomena are assumed to be 'constitutive' of higher-level ones (Sarkar, 1992). In addition to advances in theory, organizational neuroscience approaches frequently refer to the neurological constitution of human life. For instance, Becker et al. (2011: 934, emphasis added) suggest that:

Our ultimate aim is to establish an organizational neuroscience perspective that strives to understand and incorporate the cognitive machinery behind our thoughts and actions into organizational theory ... Leveraging this knowledge will reduce our level of analysis to the most basic building blocks of behavior. ${ }^{3}$

This suggests that there is an ontological link between higher and lower levels of analyses so that, for instance, entities at a higher (individual/social) level cannot alter without also altering entities at the lower (brain) level. This so-called 'supervenience' (e.g. Davidson, 1970) is, therefore, more radical than theory reduction, suggesting a monism which holds that, in Thomas Nagel's (1998: 3) words, 'everything is made of the same elements' (see also Dennett, 1996).

However, there is much scepticism about the ontological commitment to such basic elements. Thomas Nagel (1974), for instance, suggests that there is a general difficulty about psycho-physical reductions, because experience does not fit the pattern of other scientific reductions. It does not surprise that the problem of consciousness is a recurring anti-reductionist theme (Nagel, 1998; Tallis, 2011). Some have, therefore, highlighted the difficulties of finding a place for the mind in a world that is fundamentally physical (Kim, 1998), whereas others have suggested that living organisms possess 'something else' than biochemical processes - a 'vital' element that has no material manifestation (Bergson, 1988). Such processes would be of a different logical kind, and necessarily remain invisible to neuroscientific analysis.

\section{Relevance to neuroscientific study of leadership}

Our previous points suggest that the reductionist aim of achieving greater clarity and objectivity so as to arrive at a more accurate view of the real nature of leadership, for instance, by studying a leader's 'real', neurologically visible state of 'discrimination', is not necessarily achievable. What these studies fail to grasp is 'what it is like to be' that particular leader. Thomas Nagel argues that the subjective character of such experience cannot be configured in terms of an objective and singular viewpoint, as this would miss richness and detail which do 'not consist in the truth of propositions expressible in human language' (Nagel, 1974: 442). Specifically, Nagel contends that consciousness cannot be analysed by means of any explanatory systems of functional or intentional states, for these could be attributed to 'robots . . . that behaved like people though they experience nothing' (p. 436, emphasis added). But Nagel does not stop here, and delves deeper into the matter of subjective experiences and how these actively resist reduction to physical 
states or conditions. He maintains that, if facts about experiences, or facts that concern what it is like for the experiencing individual (e.g. a leader) are 'accessible only from one point of view, then it is a mystery how the true character of experience could be revealed in the physical operation of that organism [i.e. a leader]' (Nagel, 1974: 438). In this respect, Tallis (2010) reminds us that if we assume the brain to be a collection of pieces of matter, then this arrangement cannot explain experiences unless, of course, the pictures and graphs produced in neuroscientific analyses are interpreted to represent something about workplace discrimination. This, however, re-introduces observation and description or, in short, 'consciousness'.

It may further raise our suspicion that advocates of organizational neuroscience devote so much effort to the task of demonstrating the supposed triviality of the idea of consciousness. Becker et al. (2011: 948), for instance, refer to the 'binding problem', which concerns 'the conscious sense that our perceptions, thoughts, decisions, and actions result from a unitary and contemplative process, even though the underlying neural mechanisms may often be anything but unified and are frequently nonconscious'. For Becker et al., the inaccessibility of consciousness in neuroscientific approaches is not a problem, but a benefit. Because neuroscience is suggested to have direct access to the unfiltered, unordered and dispersed mechanisms that underlie the more ordered interpretations that the conscious mind makes, it erases the individual from the explanatory process, cleansing research from errors and ambiguities that lurk in respondents' self-reports.

Yet, two problems undermine this idea. First, whereas neuroscience indeed investigates biochemical processes that directly reflect mental activity prior to conscious interpretation, conscious human interpretation is still at play. The results and inferences drawn by organizational neuroscientists are the processes of their 'unitary and contemplative processes'. This effectively means that, whereas conscious processes of the research subjects are deemed distorting and replaced by scientific measurement, the thought processes of researchers are implied to be immune from such distortion. Second, philosophers of science have articulated profound objections to the neglect of consciousness. For instance, Nagel (1974) posits that conscious mental states (or the subjective experience) of an individual are not captured by any reductive processes, adding that these processes are plausibly compatible with the nonexistence of subjective experiences. This is because we lack a detailed explanation of the physical nature of a mental phenomenon (Nagel, 1974). From the neuroscientific 'view from nowhere' (Nagel, 1974), it is, therefore, impossible to understand what it is like to be a leader. Such an experience, Tallis (2010) adds, cannot be explained by the brain's response to stimuli alone, as it always entails multiple levels of awareness which are simultaneously at play.

Another line of argument against the consideration of consciousness is put forth by Lee et al. For them, consciousness and, therefore, the idea that, in the most fundamental sense, we must be more than our brains and bodies, is indicative of a 'rather self-centered view of the universe, despite its inherent attractiveness and appeal to our actual lived experiences' (Lee et al., 2012b: 213). However, we can also reverse this point and wonder whether the neuroscientific assumption that all complex processes of our environment are reducible to what goes on in our brains indicates not an equally self-centred view of the universe. This view entails the suggestion that there can be nothing outside 
the computational powers of our brains, not even consciousness or reflection, unless manifest in neuroscientific measurements. Moreover, this leaves us in the uncomfortable position where we have to wonder what consideration we should give to scholarly arguments that seemingly are made without any conscious thought as the products of bundles of biochemical reactions alone.

What is in our head is consequently not indicative of what is 'out there'. It is at best a 're-presentation' which, as Tallis (2011) observes, requires a world of phenomena, from which such re-presentations can be gained. Weick et al. (2005) emphasize the importance of understanding the difference between our mental re-presentations and the processes from which they are abstracted. Failing to distinguish both leads to the generation of paradoxes, ambiguities and contradictions which we frequently encounter in management research (Tsoukas and Hatch, 2001). It is important to highlight that this is not merely a problem of language, but also of human emotions, abstract concepts and mental activity. As Lakoff and Johnson (1980: 177) insist, 'though most of these can be experienced directly, none of them can be fully comprehended on their own terms', so that it is necessary to transfer understandings from other domains. For instance, leaders may understand an organization in terms of (the metaphor of) a machine, and find themselves uncomfortable if their experience does not match their expectations of mechanistic processes. Measuring their emotional states may thus reveal merely the difference between how they expect the world to be (i.e. transferred understandings) and the complexities of organizational life - which continually evade full comprehension and measurement. Acknowledging these wider complexities is, therefore, not taking recourse to an esoteric notion of human consciousness as organizational neuroscientists might object, but a recognition that the full and multi-textured nature of organizational processes cannot be captured by analysing the brain processes of an individual.

The empirical limitations of constitutive reductionism become evident when considering contributions from scholars interested in multi-level phenomena and leadership. For instance, Fisher and To (2012: 867) maintain that data obtained at the betweenindividuals level 'cannot be generalized automatically to relationships among apparently similar variables' at the 'within-individual' level or vice versa. They also argue that 'the underlying processes and the strength and direction of relationships can be quite different at different levels and must be investigated at each level' (p. 867). In terms of the latter, leadership scholars have long argued that what holds at one level of analysis (e.g. the individual) may not hold at another (e.g. collectives of individuals; see Yammarino and Dubinsky, 1994). Take the theory of transformational leader, for example. Burns (1978: 4) characterizes the transformational leader as someone who 'looks for potential motives in followers, seeks to satisfy higher needs, and engages the full person of the follower'. He goes on to suggest that the result 'is a relationship of mutual stimulation and elevation that converts followers into leaders' (p. 4). Proponents have consistently claimed that transformational leadership holds at the individual, group, and organizational level of analysis (Bass, 1985, 1998; Conger and Kanungo, 1998). And yet, there is empirical evidence that disconfirms this claim. Foremost here are studies by Yammarino and colleagues (Avolio et al., 1991; Avolio and Yammarino, 1990). In one study, they have confirmed that follower perceptions of transformational leadership outcomes (i.e. subordinate extra efforts, subordinate performance and effectiveness of superior) are based 
upon individual differences that exist independently of group membership in the context of sales (Yammarino and Dubinsky, 1994). In other words, the data show that transformational leadership lies in the perceptions of individual followers, and not in the perceptions of dyads or groups. The finding that transformational leadership resides in the perceptions of the beholder is further supported in a recent multi-rater transformational leadership study. The transformational leadership ratings of two team members relative to their project manager neither correlated with each other nor with ratings provided by the project managers' line manager. In fact, correlations were randomly negative or positive, and nearing a practical significance of zero (Lindebaum and Cartwright, 2010). In other words, agreement in team-level perception does not manifest itself in that study, and neither does agreement among individual raters. For the premises of ontological reductionism to hold, however, one would expect that ratings at the individual and team level would show greater convergence, which they do not.

Together, these philosophical, theoretical and empirical considerations show that ontological claims associated with constitutive reductionism are inherently problematic for the study of leadership, for they show that there is a discontinuity of effects from one level of analysis to another. Higher-order phenomena are not merely the products of lower-level processes, and attempts to reduce dyadic, group or organizational level aspects to individuals' brain activities run into the danger of producing grossly distorted ideas about how the world 'up there' really is, thereby affecting the quality of inferences drawn.

\section{Explanatory reductions}

\section{Background}

In addition to theory and constitutive reductionism, Sarkar (1992) suggests that a third form of reductionism makes explanatory claims, without necessarily clinging to the ontological commitments associated with constitutive reductions. Explanatory reductionism refers to models of reduction that imply relations of explanations, such that the reduced entity is explained by the reducing entity, irrespective of whether this entity is a theory, law or observation (Sarkar, 1992). Explanatory reductionism can be understood in terms of the wider ideal that different sciences study the same basic processes in varying degrees of aggregation, reflecting the positivist ideal of the whole of science as one coherent project (Nagel, 1998). Already, more than 50 years ago, Oppenheim and Putnam (1958) offered a succinct description of this ideal:

It is not absurd to suppose that psychological laws may eventually be explained in terms of the behavior of individual neurons in the brain; that the behavior of individual cells - including neurons - may eventually be explained in terms of their biochemical constitution; and that the behavior of molecules - including the macro-molecules that make up living cells - may eventually be explained in terms of atomic physics. If this is achieved, then psychological laws will have, in principle, been reduced to laws of atomic physics. (Oppenheim and Putnam, 1958: 7)

This ideal reverberates through the extant organizational neuroscience debate, and it is not difficult to speculate about reasons for its swift uptake. By taking the socially complex and reciprocal nature of leadership into the body, it is argued that social scientists are 
finally able to emulate the natural science by producing hard, reliable and objective data (see Blackburn, 2011; Duster, 2006). In light of this ideal, we can understand the appeal of the neuroscientific project, for instance, when Becker et al. (2011: 936) proclaim reductionism to be the 'ultimate goal of science'.

In this goal, we find a form of explanatory reduction aimed at establishing relations between rules, mechanism or fragments (Sarkar, 1992). Applied to inter-level reductions and explanations, Sarkar (1992: 176) argues that reductive explanation is the 'explanation of a whole in terms of its parts'. In the context of leadership, this implies the explanation of leadership (i.e. a social phenomenon) by way of studying brain processes depicting analogous patterns. Whereas Sarkar (1992) argues that scientific explanation tends to represent a quest for statistically pertinent factors, others go further and claim that explanations can be understood as a quest for causal factors as opposed to statistically pertinent ones (Wimsatt, 1976; see also Von Wright, 1971). This quest for causality oftentimes shines through in the arguments of advocates of organizational neuroscience (e.g. Becker et al., 2011; but see also below for more details).

Yet, when it comes to explanatory reductions, serious challenges emerge. First, in what is termed the 'multiple realizations' problem, scholars question the reducibility of psychological states to brain processes. Second, there is what we call the 'body-brain pattern', which suggests that the brain may not be the unequivocal site from which human behaviours emerge, even though signals arising from the body are integrated in higher brain regions to regulate decisions (Damasio, 2000). We discuss both in turn, and incorporate, where applicable, examples from leadership studies to remain consistent with preceding sections.

\section{Multiple realizations}

In a series of papers in the 1960s, Hilary Putnam outlined the 'multiple realizations' problem, questioning the viability of reductive explanations. This problem concerns the idea that psychological states are reducible to 'brain states' and has since been repeatedly reiterated and developed (Gillett, 2003; Schouten and de Jong, 2007; Shapiro, 2000). At its core lies the suggestion that one and the same psychological state can be realized multiply by different and distinct neural processes (Bickle, 2010). Putnam (1979: 292) argues that: "two systems can have quite different constitutions and be functionally isomorphic. For example, a computer made of electrical components can be isomorphic to one made of cogs and wheels'. Here, the problem is that, whereas the make-up of an electronic or manual computer system varies drastically, its effect - what it produces - is the same. Putnam's point is, therefore, that any psychological event-type can be realized physically in very diverse ways depending on the organism involved. This makes it almost impossible to identify any single type of neural or physical state (Kim, 1989). Applied to the neuroscientific context, this problem suggests that 'one and the same psychological kind is multiply realized by distinct physical-chemical (e.g. neural) kinds', which urges us to conclude that the idea that cognitive phenomena are 'brain-states' is problematic (Bickle, 2010: 247, emphasis in original). On the whole, the multiple realizations problem corresponds to well-worn ideas in organizational behaviour research referred to as equifinality (Martin and Fellenz, 2010). 
Moreover, in addition to the problems posed by multiple realizations of higher-level phenomena, we suggest that we can also reverse Putnam's original arguments to gain further, potentially problematic insights. Rather than only suggesting that different neurological states can lead to the same psychological state, we argue that, even if it was possible to locate particular biochemical processes or brain sections, they would be likely to lead to different higher-level effects, especially when considered from a relational perspective. For example, whether the meaning of a leader's behaviour or expression is taken literally, or if it is understood ironically, or as a joke, depends upon social reception, context and situation. For instance, a declaration of intent by a leader may in some situations be taken as invigorating, but in others as merely ridiculous. Here, the arbiter for what is realized depends not only upon what is said and done - and, therefore, on intended and unintended brain functions of the individual - but upon how these actions are realized qualitatively in a social context.

Nagel (1998) illustrates this with the example of how an old-fashioned typewriter produces a capital letter. Analysis of the mechanics involved, the construction and movement of the button and lever raising the carriage so that the capital letter hits the roll, remains necessarily mute about what such a letter does, say, in the structure of a sentence or in the flow of written conversation. Similarly, the study of a leader's anticipation of their influence, and their respective brain patterns, cannot shed light on the social effects of their statements. The same processes on the neurological level may thus lead to vastly different 'multiple' realizations at the higher level. This is a problem probably all of us have experienced when telling a joke which some members of the audience have heard before but for others it is the first time. Prone to this kind of multiple realization problem are, in particular, 'conventional' properties, which gain meaning only in relation to other constituents and, therefore, emerge only on higher levels without being reducible to more basic ones. For instance, conventions of language and money, but also conventions of morality, jokes or irony, are inexplicable on the basis of their physical attributes, grammatical structures, or in terms of the behaviours of individuals alone (Nagel, 1998).

Fundamental explanations cannot, therefore, be neatly applied to complex systems on higher levels and account for the workings of these levels satisfactorily. Qualitative differences exist on each level of abstraction where 'entirely new laws, concepts, and generalizations are necessary, requiring inspiration and creativity to just as great a degree as in the previous one' (Anderson, 1972: 393). But there are also problems of quantity. Explanatory reductions are likely to become unwieldy, for they run against the twin difficulties of scale and complexity. These accrue, for instance, if we try to communicate weather forecasts primarily in terms of the behaviours of individual molecules, or analyse the very real problems of the rest of science through elementary particle physics. Here, any possible benefit of the reduction is absorbed by the increase in complexity and unwieldiness of the resulting explanation. Such attempts are, therefore, quite impractical, as we would struggle computing the information to attain any meaningful insights (Anderson, 1972; Nagel, 1998).

\section{Body-brain pattern}

A second problem stems from the assumed directionality of causal relations. Much of the advocacy of using neuroscience when studying organizational problems converges on a 
'bottom-up' approach (i.e. from the brain up to the social sphere) in explaining human behaviour. Here, the brain is isolated as the 'primal cause of behaviour' (Becker et al., 2011: 934) - the ultimate referent from which most (if not all) impulses emanate, and in which all primary behavioural triggers occur (Boyatzis, 2011; Senior et al., 2011). Further examples exist in the leadership literature. For instance, although Balthazard et al. (2012: 244, emphasis added) discuss the 'potential [neurological] correlates of transformational leadership behavior', they also refer to the 'neurological mechanisms that may underpin the transformational leadership qualities of individuals'. Similarly, Boyatzis (2011) claims that 'if you believe that leadership involves inspiring others and motivating them to be their best and develop, learn, adapt and innovate, then activating the parts of their brain that will help requires arousing what we have called the Positive Emotional Attractor' (no page number available, emphasis added). It is important to acknowledge that there are some cautionary remarks about the existing technological and methodological problems to the exploitation of the explanatory power of neuroscience (Lee et al., 2012a). However, some scholars go as far as to propose that we can use, inter alia, 'neuroscience ... to reverse engineer the ingredients of good leadership' (King et al., 2009: 915, emphasis added). Conceived in this way, brain processes are suggested not only to explain higher-order phenomena, but also to precede them, and thus seemingly qualify as a cause for human behaviour. However, serious concerns exist about such an explanatory logic and, in particular, about the taken-for-granted directionality of causality from brain to body.

These problems become apparent when considering the logic of causality. Here, we turn to the work of Antonakis et al. (2010), who detail three pre-conditions of causality. For two events ( $x$ and $y$ ) to be related causally: (i) $x$ must temporally precede $y$; (ii) $x$ must be reliably correlated with $y$ (beyond chance); and (iii) the relationship between $x$ and $y$ must not be accounted for by other causes. Applying this framework to the neuroscientific investigations at the brain level as a means of drawing causal inferences for human behaviour, we can identify a number of problems. The first precondition relates to the assumed directionality of the body-brain pattern, whereas the second and third indicate difficulties when reducing the complex and interrelated bodily patterns to clearly identifiable locations.

With regard to the first condition, the experimental branch of psychology proffers compelling evidence for the existence of a bottom-up mechanism (i.e. from the body to the brain), indicating that causality may very well run in the reverse direction. Zajonc (1980, 1984), for instance, argues against the prevailing view that a cognitive appraisal (as it occurs in the brain) always precedes an emotion. He posits that affect is often encoded in 'visceral or muscular symbols' without having direct verbal referents (Zajonc, 1980: 158). This is demonstrated by various electromyographic studies that strongly demonstrate the involvement of muscular activity 'in the imagination, recall, and production of emotional states' (Zajonc, 1980: 158). For Zajonc, this is evidence that affective processing is more proximal to the acquisition and retention of motor skills than to lists of words. In other words, muscular activities can also send signals 'upwards' to the brain, which, in turn, can cause and influence emotional states. A number of recent studies in experimental psychology have further underpinned Zajonc's arguments. For instance, researchers have shown that past personal life events can be 
more easily accessed when the body is in the same position as it was in the original experience (Dijkstra et al., 2007; Riskind, 1983). Similarly, Casasanto and Dijkstra (2010) have shown that negative or positive life experiences are implicitly linked to schematic representations of downward and upward bodily movements, so that the seemingly meaningless action of moving marbles upwards 'can cause people to think more positive thoughts' (p. 179). Like Zajonc's (1984) contention that finding evidence in only one situation on the primacy of affect over cognition would confirm the independence hypothesis, so does a singular occurrence of the body-brain pattern falsify the hypothesis that only activities in the brain cause human behaviour. This suggests that brain activity does not exclusively cause human behaviour, but that it is at least partly the product of bodily processes, so that the brain is merely one factor in the more intricately interrelated pathways of communication that, together, account for human behaviour.

Moreover, there are concerns about the second criteria for causal inferences (i.e. that $x$ must be reliably and beyond chance correlated with $y$ ), as correlations between brain processes and psychological phenomena and human behaviour remain elusive. Such problems are partly recognized in recent organizational neuroscience debates. For instance, Lee et al. (2012a) suggest that the:

... colorful imagery that is often presented with the findings of brain imaging studies merely indicates the level of confidence that we have with regards to whether the particular region of the brain is somehow implicated in the task. Simply put, with the data available in such cases, it is impossible to infer a lack of involvement in a region which is not shown as activated. (Lee et al., 2012a: 925, emphasis added)

As a resolution, Lee et al. (2012a) invoke the 'pure insertion hypothesis', which posits that the engendered activity specific to one particular task does not change when other tasks are added. To demonstrate that a particular brain region is causally linked with a particular task, the 'pure insertion hypothesis' must be satisfied. This, they admit, may be difficult to achieve (Lee et al., 2012a), and the limitations of functional brain imaging are further explicated by Wastell and White (2012).

In light of the difficulty in disentangling how activation (or lack thereof) in one or more brain region is associated with particular tasks, Vul et al. (2009) have pondered whether this ignores a fundamental assumption of parametric testing (i.e. independence of observations). Specifically, disentangling whether activation in one or more brain regions is associated reliably with particular tasks is rendered problematic by the failure of researchers to define the brain regions under scrutiny independently of the experimental manipulation. Given that many brain regions are measured in a scan, there are (in effect) multiple dependent variables; by chance alone a subset of these regions may show an effect of the manipulation (this, we note, represents an empirical extension of the multiple realization problem). The tendency of some brain researchers to base their statistical analysis on particular subsets of the brain entails that the strength of the correlation will be considerably inflated. Vul et al. (2009) show how this 'non-independence error' can produce statistically significant correlations from simulated brain activity which is pure noise. 
Antonakis et al.'s (2010) final condition posits that correlations between $x$ and $y$ must not be accounted for by other causes. That is, activity in one brain region does not only cause a specific behaviour to occur, but there is a confounding variable that influences that behaviour as well. For instance, studies on the experience of emotions suggest that, even if the experience of emotion may be reduced causally to brain activity, emotions are not entirely synonymous with specific features such as neural circuitry, synaptic changes or biochemical properties (Feldman Barrett et al., 2007). It is for this reason that 'content cannot be entirely reduced to its causes' because any 'conscious event has both neurobiological and phenomenological features' (Feldman Barrett et al., 2007: 376, emphasis added). It is these phenomenological influences (i.e. lived experiences), we argue, that pose a threat to this pre-condition of causal inferences.

Our consideration on the three preconditions for causality hold important implications for the explanatory power of neuroscientific approaches in management. In particular, they suggest that the brain may not be the only site to which human behaviour can legitimately be reduced. Although the brain unquestionably plays an important role (Becker and Cropanzano, 2010; Lee et al., 2012b; Senior et al., 2011), it may not always be the starting point triggering human behaviour. It may be, as argued by Zajonc (1984), subject to other, more primary, bodily functions under certain conditions. The question is, therefore, whether we can, with any degree of certainty, isolate the brain's neurological activity as the sole and consistent producer of such aggregate phenomenal impressions (see Feldman Barrett et al., 2007). If we cannot, then the quality of inferences drawn from studies in the domain of organizational neuroscience must be questioned.

\section{Conclusions}

In our analysis, we have scrutinized and challenged the assumed possibilities and benefits of reductionism in the neuroscientific study of leadership. Although, previously, reductionism had been formulated largely in hypothetical terms, advances in technologies and methods have turned the reductive ideal into a seductively real and tangible possibility. We have argued that, whereas the promising insights of neuroscientific approaches for the study of leadership have been embraced enthusiastically, fundamental concerns about the viability of such promises have been largely ignored.

For the purpose of our analysis, we have enlisted Sarkar's (1992) threefold categorization of reductionism and have outlined problems and concerns in each variant using leadership examples. We highlighted that all three types of reductionism populate current debates on organizational neuroscience. First, understood as a reduction of theory, advocates of organizational neuroscience face the challenge of bridging heterogeneous idioms and logics and, if possible at all, thereby risk inflating (rather than reducing) complexity and ambiguity in their theoretical accounts. We then considered constitutive reductionism, which makes ontological claims about the constitutive relationship between brain processes and human behaviour. We have shown that ontological claims are problematic because the properties and processes that make up one level of analysis do not strictly correspond to properties and processes operating at another level. In addition, we have expressed scepticism about the putative possibility to access brain patterns directly and thereby circumvent otherwise distorting 
influence of human consciousness by way of neuroscientific methods. Crucially, we find the ideal of a dehumanized scientific analysis fallacious, for it negates the influence of the researcher as a consciously interpreting human being in the research process. It also neglects that human behaviour is essentially relational, rendering social phenomena, such as leader-follower interactions, irreducible to the thought processes of one individual alone. Finally, we have scrutinized explanatory reductionism, which suggests the possibility of identifying consistent patterns of explanation across varying hierarchical levels. Here, we identified two major critiques. First, we have suggested the possibility of double-ended 'multiple realizations', where each micro-phenomenon may have multiple correspondents on a macro level, and vice versa. Second, we have introduced the 'body-brain-pattern', which suggests that the brain level is not always the ultimate cause of human behaviour, but merely one part of more complexly unfolding processes.

It is critically important to underline that, although all three types of reductionism have their distinguishing features, they all point out and underscore that the quality of inferences drawn from organizational neuroscientific research as they relate to measurement and intervention is likely to suffer. As a result, where advocates of neuroscience currently claim the validity of their findings, we can, in fact, find considerably more ambiguity than is presently recognized. We, therefore, put the onus upon advocates of organizational neuroscience to demonstrate how the theoretical, ontological and explanatory challenges associated with reductionism can be resolved. Moreover, they have to show how these solutions can be translated methodologically in empirical designs to ensure that trustworthy conclusions can be drawn from these studies.

The prevailing ambiguities about the processes of organizational neuroscience may also caution us against the putative possibility of scientifically engineering organizationally desirable outcomes on the basis of 'hard' and 'reliable' units of analysis. On the contrary, we should be careful not to replace the many existing units of analysis. The scientific ideal of replacing the seemingly unreliable variable of the 'human being' with scientifically established facts that are immune to errors, changing opinions or lies to achieve a 'view from nowhere' (Nagel, 1974), is both illusory and problematic. Neuroscientific research processes, like any other form of research activity, are subject to various translations and interpretations that connect laboratory results with the multi-level nature of organizational work (see Latour and Woolgar, 1979). These are accomplished by conscious and reflective human beings, and are thus prone to the influence of bias or short-sightedness, as well as political interests and personal aims of those involved (Rose and Rose, 2012; Zundel and Kokkalis, 2010). In a way, retaining a sense of leaders as thinking and feeling individuals may compel us to consider explicitly the role of the consciously thinking researcher in the generation of scientific results, encouraging us more critically to reflect upon what our attempts at optimizing and normalizing behaviour may do to those who become subjected to neuroscientific re-engineering treatments. The ethical connotations of this development have been recognized in a recent exchange of diverging opinions (e.g. Ashkanasy, in press; Cropanzano and Becker, in press; Lindebaum, in press).

It is important to underline that the neuroscientific research paradigm is itself fluid and developing. We have noted that the 'brain' and 'neurons' are also concepts that may 
be further reduced to the workings of atoms or chemicals, and that it is likely that future technical developments will again significantly shift research focus from neuro-images to biochemical compositions or other units of analysis. The current version of neuroscience will, therefore, not be the final, all-solving approach to studying organizations. It merely indicates ongoing scientific progress coupled with technological advances. Thus, we suggest that there is a place for a variety of concepts and forms of inquiry at different levels of analysis, and that the divergence between them, rather than their unification, is indicative of a rich and thriving community of investigations.

Some important corollaries for organizational practice flow from the excitement surrounding neuroscience as a producer of hard and robust data. In particular, if the potency of neuroscience is linked with its ability to single out effective leaders (inspirational leaders qualify for this category according to Waldman et al., 2011), then leadership scholars and practitioners are likely to be enticed by it (see Balthazard, 2011). This may be particularly the case in times of economic crisis (Crotty, 2009). And yet, given the inference issues we identified, this would seem to cement the imperative to revisit traditional social science disciplines, such as sociology or psychology, to continue examining socially complex phenomena (see Edwards, 2012), such as leadership. Somewhat ironically, the 10 to 25 per cent of variance explained in outcomes by traditional leadership predictors (Barrick and Mount, 1991; Bass and Bass, 2009) may not be such a second-class choice as advocates of organizational neuroscience (see Waldman et al., 2011) portray them to be. We urge, therefore, leadership scholars and practitioners not to be 'blinded by neuroscience' (Wastell and White, 2012: 339) when the question arises whether or not it should be employed as a recruitment or development tool. At present, it seems improbable to us that we can conclude with certainty that effective leaders can be identified and developed by way of neuroscientific methods. In addition to the inference issues we have outlined, another source of doubt in this regard lies in the contextual nuances that render a leader effective in one situation but not another (Lindebaum and Fielden, 2011). In this regard, Ghoshal (2005) reminds us of the potential damage that 'bad' management theories can have for organizational practice.

To conclude, we harbour no illusions that neuroscience will continue to significantly influence the research agenda in leadership and elsewhere. As Farah (2005) reminds us, it is not a question of whether or not, but how and when neuroscience will form and shape our future. However, given the many concerns and questions that remain, we suggest that a first step in the right direction is to abandon the expectation that organizational neuroscience can single-handedly 'revolutionize' our understanding of leadership. Instead, we argue that it is potentially one form of inquiry amongst many valid and important ones.

\section{Acknowledgements}

A previous version of this article has been presented at the European Group for Organization Studies in Helsinki, 5-7 July 2012. We extend our gratitude to Peter J Jordan and David Wastell for providing very useful suggestions on an earlier draft of this article. In the same vein, Associate Editor Gail Fairhurst and two anonymous reviewers deserve full credit for their constructive guidance through the review process. 


\section{Funding}

This research received no specific grant from any funding agency in the public, commercial or not-for-profit sectors.

\section{Notes}

1. The authors are listed in alphabetical order. Both authors contributed equally to this article.

2. Importantly, neuroscientists themselves often recognize the limitations of reductionism when it comes to studying the complexity of the human brain. In fact, some neuroscientists are explicitly warning against a sole focus upon reductionist (i.e. analytical) approaches to their research at the expense of holistic (i.e. synthetic) insights. Precisely, it is argued that 'the problem occurs when neuroscientists assume the superiority of one approach over the other' (Cahill et al., 2001: 579). We argue that, in the process of transferring neuroscientific knowledge into their domain, leadership scholars do not pay sufficient heed to this injunction when they follow the reductionist route.

3. If reductionist thinking is carried further, one could object here that the most basic building block of human behaviour does not reside in the cognitive machinery behind our thoughts, but at the level of atomic physics (see quote by Oppenheim and Putnam, 1958, detailed later). Ironically, therefore, what is described as a most basic building block of human behaviour by advocates of organizational neuroscience may actually not penetrate to the potentially deepest level of analysis possible.

\section{References}

Anderson PW (1972) More is different. Science 177(4047): 393-396.

Antonakis J, Bendahan S, Jacquart P and Lalive R (2010) On making causal claims: A review and recommendations. The Leadership Quarterly 21(6): 1086-1120.

Antonakis J, Fenley M and Liechti S (2011) Teaching leadership - can charisma be taught? Tests of two interventions. Academy of Management Learning \& Education 10(3): 374-396.

Ashkanasy NM (in press) Neuroscience and leadership: Take care not to throw the baby out with the bathwater. Journal of Management Inquiry.

Avolio BJ and Yammarino FJ (1990) Operationalizing charismatic leadership using a levels-ofanalysis framework. The Leadership Quarterly 1(3): 193-208.

Avolio BJ, Yammarino FJ and Bass BM (1991) Identifying common methods variance with data collected from a single source: An unresolved sticky issue. Journal of Management 17(3): 571-587.

Balthazard PA (2011) Using neuroscience to learn how to build a better leader. Available at: http:// knowwpcarey.com/article.cfm?aid=24 (accessed 20 December 2012).

Balthazard PA, Waldman DA, Thatcher RW and Hannah ST (2012) Differentiating transformational and non-transformational leaders on the basis of neurological imaging. The Leadership Quarterly 23(2): 244-258.

Barrick MR and Mount MK (1991) The Big Five personality dimensions and job performance: A meta-analysis. Personnel Psychology 44(1): 1-26.

Bass BM (1985) Leadership and Performance Beyond Expectations. New York: Free Press.

Bass BM (1998) Current developments in transformational leadership: Research and applications. Invited address to the American Psychological Association, San Francisco, August.

Bass BM and Bass R (2009) The Bass Handbook of Leadership: Theory, Research, and Managerial Applications. New York: Free Press.

Bateson G (1972) Steps to an Ecology of Mind. Chicago: University of Chicago Press.

Becker WJ and Cropanzano R (2010) Organizational neuroscience: The promise and prospects of an emerging discipline. Journal of Organizational Behavior 31(7): 1055-1059.

Becker WJ, Cropanzano R and Sanfey AG (2011) Organizational neuroscience: Taking organizational theory inside the neural black box. Journal of Management 37(4): 933-961. 
Bergson H (1988) Matter and Memory. New York: Zone Books.

Bickle J (2010) Has the last decade of challenges to the multiple realization argument provided aid and comfort to psychoneural reductionists? Synthese 177(2): 247-260.

Blackburn S (2011) The seat of knowledge: Smart and comfortable. Times Higher Education, 19-25 May: 40-42.

Boyatzis RE (2011) Neuroscience and leadership: The promise of insights. Ivey Business Journal (Jan/Feb). Available at: http://www.iveybusinessjournal.com/topics/leadership/neuroscience-and-leadership-the-promise-of-insights, - .UNL5DbY1cXw (accessed 20 December 2012).

Cahill L, Mcgaugh JL and Weinberger NM (2001) The neurobiology of learning and memory: Some reminders to remember. Trends in Neurosciences 24(10): 578-581.

Casasanto D and Dijkstra K (2010) Motor action and emotional memory. Cognition 115(1): 179-185.

Conger JA and Kanungo RN (1998) Charismatic Leadership in Organizations. Thousand Oaks, CA: SAGE.

Cropanzano R and Becker WJ (in press) The promise and peril of organizational neuroscience: Today and tomorrow. Journal of Management Inquiry.

Crotty J (2009) Structural causes of the global financial crisis: A critical assessment of the 'new financial architecture'. Cambridge Journal of Economics 33(4): 563-580.

Cunliffe AL (2009) The philosopher leader: On relationalism, ethics and reflexivity-A critical perspective to teaching leadership. Management Learning 40(1): 87-101.

Cunliffe AL and Eriksen M (2011) Relational leadership. Human Relations 64(11): 1425-1449.

Damasio AR (2000) The Feeling of What Happens: Body and Emotion in the Making of Consciousness. London: Vintage.

Davidson D (1970) Mental events. In: Foster L and Swanson J (eds) Experience and Theory. Amherst, University of Massachusetts, 79-101.

Dennett DC (1996) Darwin's Dangerous Idea: Evolution and the Meanings of Life. London: Penguin.

Dijkstra K, Kaschak MP and Zwaan RA (2007) Body posture facilitates retrieval of autobiographical memories. Cognition 102(1): 139-149.

Duster T (2006) Comparative perspectives and competing explanations: Taking on the newly configured reductionist challenge to sociology. American Sociological Review 71(1): 1-15.

Edwards P (2012) Experimental economics and workplace behaviour: Bridges over troubled methodological waters? Socio-Economic Review 10(2): 293-315.

Fairhurst G (2009) Considering context in discursive leadership research. Human Relations 62(11): $1607-1633$.

Farah MJ (2005) Neuroethics: The practical and the philosophical. Trends in Cognitive Sciences 9(1): 34-40.

Fazekas P (2009) Reconsidering the role of bridge laws in inter-theoretical reductions. Erkenntnis 71(3): 303-322.

Feldman Barrett L, Mesquita B, Ochsner K and Gross J (2007) The experience of emotion. Annual Review of Psychology 58: 373-403.

Felin T, Foss NJ, Heimeriks KH and Madsen TL (in press) Microfoundations of routines and capabilities: Individuals, processes, and structure. Journal of Management Studies.

Feyerabend PK (1962) Explanation, reduction, and empiricism. In: Feigl H and Maxwell G (eds) Minnesota Studies in the Philosophy of Science III. Minneapolis, University of Minnesota Press, 28-97.

Fisher CD and To ML (2012) Using experience sampling methodology in organizational behavior. Journal of Organizational Behavior 33(7): 865-877. 
Franklin J (1987) Molecules of the Mind: The Brave New Science of Molecular Psychology. New York: Atheneum.

Ghoshal S (2005) Bad management theories are destroying good management practices. Academy of Management Learning \& Education 4(1): 75-91.

Gillett C (2003) The metaphysics of realization, multiple realization, and the special sciences. Journal of Philosophy 100(11): 591-603.

Guba EG and Lincoln YS (1994) Competing paradigms in qualitative research. In: Denzin NK and Lincoln YS (eds) Handbook of Qualitative Research. Thousand Oaks, CA: SAGE, 105-117.

Hobfoll SE (2001) The influence of culture, community, and the nested-self in the stress process: Advancing conservation of resources theory. Applied Psychology: An International Review 50(3): 337-421.

Kaiser MI (2012) Why it is time to move beyond Nagelian reduction. The Philosophy of Science in a European Perspective 3(2): 245-262.

Kim J (1989) The myth of nonreductive materialism. Proceedings and Addresses of the American Philosophical Association 63(3): 31-47.

Kim J (1998) Mind in a Physical World: An Essay on the Mind-Body Problem and Mental Causation. Cambridge, MA: MIT Press.

King AJ, Johnson DDP and Van Vugt M (2009) The origins and evolution of leadership. Current Biology 19(19): 911-916.

Krasikova DV and LeBreton JM (2012) Just the two of us: Misalignment of theory and methods in examining dyadic phenomena. Journal of Applied Psychology 97(4): 739-757.

Lakoff G and Johnson M (1980) Metaphors We Live By. Chicago, IL: University of Chicago Press.

Latour B and Woolgar S (1979) The Social Construction of Scientific Facts. Beverly Hills: SAGE.

Lee N, Senior C and Butler M (2012a) The domain of organizational cognitive neuroscience: Theoretical and empirical challenges. Journal of Management 38(4): 921-931.

Lee N, Senior C and Butler M (2012b) Leadership research and cognitive neuroscience: The state of this union. The Leadership Quarterly 23(2): 213-218.

Lindebaum D (in press) Pathologizing the healthy but ineffective: Some ethical reflections on using neuroscience in leadership research. Jounal of Management Inquiry.

Lindebaum D and Cartwright S (2010) A critical examination of the relationship between trait emotional intelligence and transformational leadership. Journal of Management Studies 47(7): 1317-1342.

Lindebaum D and Fielden SL (2011) 'It's good to be angry': Enacting anger in construction project management to achieve perceived leader effectiveness. Human Relations 64(3): 437-458.

Martin J and Fellenz MR (2010) Organizational Behaviour \& Management. Andover: Cengage Learning EMEA.

Meindl JR (1995) The romance of leadership as a follower-centric theory: A social constructionist approach. Leadership Quarterly 6(3): 329-341.

Nagel E (1961) The Structure of Science. New York: Harcourt, Brace and World.

Nagel T (1974) How is it like to be a bat? The Philosophical Review LXXXIII(4): 435-450.

Nagel T (1998) Reductionism and antireductionism. In: Foundation N (ed.) The Limits of Reductionism in Biology: Symposium 213. Chichester, Wiley.

Nicholson N and White R (2006) Darwinism - a new paradigm for organizational behavior? Journal of Organizational Behavior 27(2): 111-119.

Oppenheim P and Putnam H (1958) Unity of science as a working hypothesis. In: Feigl H, Scriven M and Maxwell G (eds) Concepts, Theories, and the Mind-Body Problem. Minneapolis, University of Minnesota Press, 3-36.

Pinker S (2002) The Blank Slate: The Modern Denial of Human Nature. New York: Viking.

Putnam H (1979) Philosophy and our mental life. In: Putnam H (ed.) Mind, Language and Reality. Cambridge, UK, Cambridge University Press, 291-303. 
Riskind JH (1983) Nonverbal expressions and the accessibility of life experience memories: A congruence hypothesis. Social Cognition 2(1): 62-86.

Rose H and Rose S (2012) Genes, Cells and Brains: The Promethean Promises of the New Biology. London: Verso.

Sarkar S (1992) Models of reduction and categories of reductionism. Synthese 91(3): 167-194.

Schouten M and de Jong HL (2007) Mind matters: The roots of reductionism. In: Schouten M and de Jong HL (eds) The Matter of the Mind: Philosophical Essays on Psychology, Neuroscience, and Reduction. Oxford, Blackwell, 1-28.

Senior C, Lee N and Butler M (2011) Organizational cognitive neuroscience. Organization Science 22(3): 804-815.

Shapiro J (2000) Multiple realizations. Journal of Philosophy 97(12): 635-654.

Shotter J (2010) Perplexity: Preparing for the happenings of change. In: Lowe S (ed.) Managing in Changing Times: A Guide for the Perplexed Manager. Los Angeles, CA: Response Books.

Tallis R (2010) What neuroscience cannot tell us about ourselves. The New Atlantis (Fall): 3-25.

Tallis R (2011) Aping Mankind: Neuromania, Darwinitis, and the Misrepresentation of Humanity. Durham, UK: Acumen Publishers.

Tsoukas H and Hatch MJ (2001) Complex thinking, complex practice: The case for a narrative approach to organizational complexity. Human Relations 54(8): 979-1013.

Von Wright GH (1971) Explanation and Understanding. New York: Cornell University Press.

Vul E, Harris C, Winkielman P and Pashler H (2009) Puzzlingly high correlations in fMRI studies of emotion, personality, and social cognition. Perspectives on Psychological Science 4(3): 274-290.

Waldman DA, Balthazard PA and Peterson SJ (2011) Leadership and neuroscience: Can we revolutionize the way that inspirational leaders are identified and developed? Academy of Management Perspectives 25(1): 60-74.

Wastell D and White S (2012) Blinded by neuroscience social policy, the family and the infant brain. Families, Relationships and Societies 1(3): 399-416.

Weick KE, Sutcliffe KM and Obstfeld D (2005) Organizing and the process of sensemaking. Organization Science 16(4): 409-421.

Wimsatt WC (1976) Reductive explanation: A functional account. Boston Studies in the Philosophy of Science 32: 671-710.

Yammarino FJ and Dubinsky AJ (1994) Transformational leadership theory: Using levels of analysis to determine boundary conditions. Personnel Psychology 47(4): 787-811.

Zajonc RB (1980) Feeling and thinking: Preferences need no inferences. American Psychologist 35(2): 151-175.

Zajonc RB (1984) On the primacy of affect. American Psychologist 39(2): 117-123.

Zundel M and Kokkalis P (2010) Theorizing as engaged practice. Organization Studies 31(9-10): $1209-1227$.

Dirk Lindebaum is a Reader in management at University of Liverpool Management School, UK. He holds a PhD from Manchester Business School in Organizational Psychology. One stream of his research activities pertains to organizational phenomena that involve emotional processes, such as emotional intelligence and leadership, as well as issues of conformity, power and deviance. Another stream that he has pursued of late concerns the increasing visibility of neuroscientific theories and methods in the study of organizational behaviour. [Email: d.lindebaum@liverpool.ac.uk]

Mike Zundel is a Senior Lecturer in management at the University of Liverpool Management School, UK. His work focuses on organizational practice theory and institutional theory, as well as the sociology of science and the academic knowledge production process. Connecting these strands is his interest in the complex relational patterns that connect individuals and wider organizational contexts, and how these relations can be understood in terms of processes. [Email: zundel@liverpool.ac.uk] 